\title{
Morphological Transformation of Silver Nanoparticles from Commercial Products: Modeling from Product Incorporation, Weathering through Use Scenarios, and Leaching into Wastewater
}

\author{
Selvan Mohan ${ }^{1}$, Juliska Princz ${ }^{2}$, Banu Ormeci ${ }^{3}$ and Maria C. DeRosa ${ }^{1, *(1)}$ \\ 1 Department of Chemistry, Carleton University, 1125 Colonel by Drive, Ottawa, ON K1S 5B6, Canada \\ 2 Environment and Climate Change Canada, 335 River Road South, Ottawa, ON K1V 1C7, Canada \\ 3 Department of Civil and Environmental Engineering, Carleton University, 1125 Colonel by Drive, \\ Ottawa, ON K1S 5B6, Canada \\ * Correspondence: maria.derosa@carleton.ca; Tel.: +613-520-2600 (ext. 3844)
}

Received: 19 July 2019; Accepted: 25 August 2019; Published: 5 September 2019

\begin{abstract}
There is increasing interest in the environmental fate and effects of engineered nanomaterials due to their ubiquitous use in consumer products. In particular, given the mounting evidence that dramatic transformations can occur to a nanomaterial throughout its product lifecycle, the appropriateness of using pristine nanomaterials in environmental testing is being questioned. Using a combination of transmission electron microscopy (TEM), energy dispersive X-ray spectroscopy (EDS), X-ray photoelectron spectroscopy (XPS), and inductively coupled plasma-mass spectrometry (ICP-MS), this work examines the morphological and compositional effects of conditions mimicking a typical lifecycle of a nano-enabled product, from the production of the silver nanoparticle (AgNP)-laden textiles, through its use, laundering, and then finally, its leaching and incubation in the wastewater collection system. These simulated weathering conditions showed evidence for the transformation of $\mathrm{AgNPs}$ into $\mathrm{AgCl}$ and $\mathrm{Ag}_{2} \mathrm{~S}$. Incubation in raw wastewater had the most dramatic effect on the AgNPs in terms of transformation, no matter what initial weathering was applied to the NPs prior to incubation. However, despite extensive transformation noted, AgNPs were still present within all the samples after the use scenarios.
\end{abstract}

Keywords: nanoparticle; Silver (Ag); life cycle; TEM; EDS; ICP-MS; XPS

\section{Introduction}

The unique properties of nanoparticles (NPs) make them attractive additives in a variety of commercial products. With the heightened interest in this area of research has come a plethora of novel nanomaterials of varying composition and morphology, many with attractive possible applications $[1,2]$. Of the over 1600 products claiming to contain nanomaterials, 383 of them explicitly declare the incorporation of silver [3]. Although AgNPs are applied to many different commercial products worldwide, the majority of them are used in textiles for antimicrobial purposes [4-7]. The ubiquity of AgNP-laden products in the marketplace sparks the question of the eventual environmental fate and effects of these materials.

Studies on the environmental impact of nanoparticles are typically carried out using the material in pristine form and vary widely in size $(10-50 \mathrm{~nm})$ and coatings depending on the availability and ease of synthesis of the nanoparticles [8-14]. Numerous studies have established the potential ecotoxicological effects of AgNPs. They inhibit the photosynthesis of algae, increase the mortality rate of aquatic zebrafish embryos, and disrupt microbial colonies in soil [14-21]. While an understanding of the 
potential impact of pristine nanoparticles on the environment is essential, particularly in simulating accidental spill scenarios, these results might not be universally applicable to all exposure situations, given the transformations that NPs could undergo throughout their life cycle [22]. Transformations can include the agglomeration or aggregation of the nanoparticle or a chemical/surface transformation triggered by exposure to other agents within the product or exposed to the product. Although often used interchangeably, aggregation is defined as the loose assembly of particles and agglomeration is the more permanent assembly of the particles into tight clusters causing partial fusion [23]. Several studies have already established that transformations to $\mathrm{AgCl}$ or $\mathrm{Ag}_{2} \mathrm{~S}$ are possible for $\mathrm{AgNPs}$ [24]. This transformation has been previously described as oxidative dissolution by chlorine and sulfidation, respectively $[25,26]$. However, the presence of chloride, nitrate, selenide, and sulfide have also been known to lead to AgNPs transformations [27-29]. Indeed, analyzing transformed NPs and subsequent byproducts released from the use of products containing NPs will inform environmental fate and toxicological studies, as well as risk assessment initiatives [30].

With regards to Ag, studies have shown that AgNPs are released from AgNP-laden fabric using only water washes $[31,32]$. Treatments with sweat and detergent have also been shown to trigger the release of NPs [33-35]. The composition, $\mathrm{pH}$, and ionic strength of these solutions will contribute to the variability in the form of Ag extracted [24]. As the fabrics are exposed to these conditions (e.g., washing, sweat.), the potential is high that the leachates from the consumer product, containing transformed AgNPs, will eventually end up in the wastewater treatment process [36]. However, even before reaching the wastewater treatment facility, incubation in the wastewater collection system could further transform the nanomaterials. Pristine nanoparticles are known to disrupt microbial colonies, biofilms, and alter the chemical properties of the wastewater, hindering the effectiveness of the wastewater treatment [37-39]. Further transformation of these AgNPs can be expected through the wastewater treatment, as well as during environmental weathering [40-42]. Finally, sludge from wastewater is treated for use in agricultural applications [43]. The transformation of $A g N P s$ to $\mathrm{Ag}_{2} \mathrm{~S}$ when added directly to the sludge, had been reported [44]. $\mathrm{Ag}_{2} \mathrm{~S}$ nanoparticles of 5 to $10 \mathrm{~nm}$ have also been independently detected in sewage sludge [45].

A clearer understanding of the physical and chemical changes that take place throughout the lifecycle of a nano-enabled product would help inform toxicological studies and improve our risk assessment for nanomaterials. In this paper, the morphology and composition of AgNPs, when embedded into fabric, are compared following a variety of treatments meant to mimic several stages in the lifecycle of the nanomaterial, from initial product incorporation to use and washing, to right before the wastewater treatment process (Figure 1).

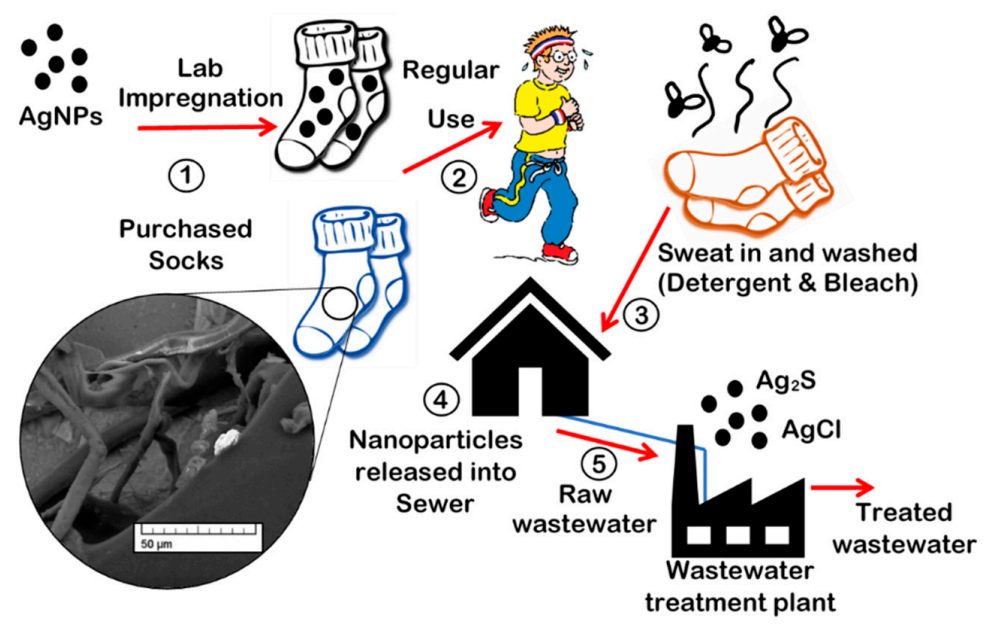

Figure 1. Overview of the path of potential transformations for silver nanoparticles (AgNPs) studied in this paper. 


\section{Materials and Methods}

Pristine AgNPs, $25 \pm 3 \mathrm{~nm}$ Econix Silver Nanospheres $(5 \mathrm{mg} / \mathrm{mL}$ concentration, $-23 \mathrm{mV}$ zeta potential) were purchased from Nanocomposix, San Diego, CA, USA (Figure 2). Socks with AgNPs (Sports Socks) were purchased from Nanosilver, Olomouc, Czech Republic (commercial socks). White Hanes sport cut socks (Winston-Salem, NC, USA), Clorox ${ }^{\circledR}$ bleach (Oakland, CA, USA) and TideßOriginal laundry detergent (Procter \& Gamble, Cincinnati, OH, USA) were used as received. Raw wastewater (filtered to remove large solid matter) was obtained from the influent of the Robert O. Pickard Environmental Centre wastewater plant (Ottawa, ON, Canada). Transmission electron microscopy (TEM) grids were purchased from Electron Microscopy Sciences, Hatfield, PA, USA. All acids used were ultrapure reagent grade unless specified. Only double deionized water $\left(\mathrm{ddH}_{2} \mathrm{O}\right)$ was used in this experiment. All other chemicals were purchased from Sigma Aldrich (MilliporeSigma Canada Co., Oakville, ON, Canada) and used as received.

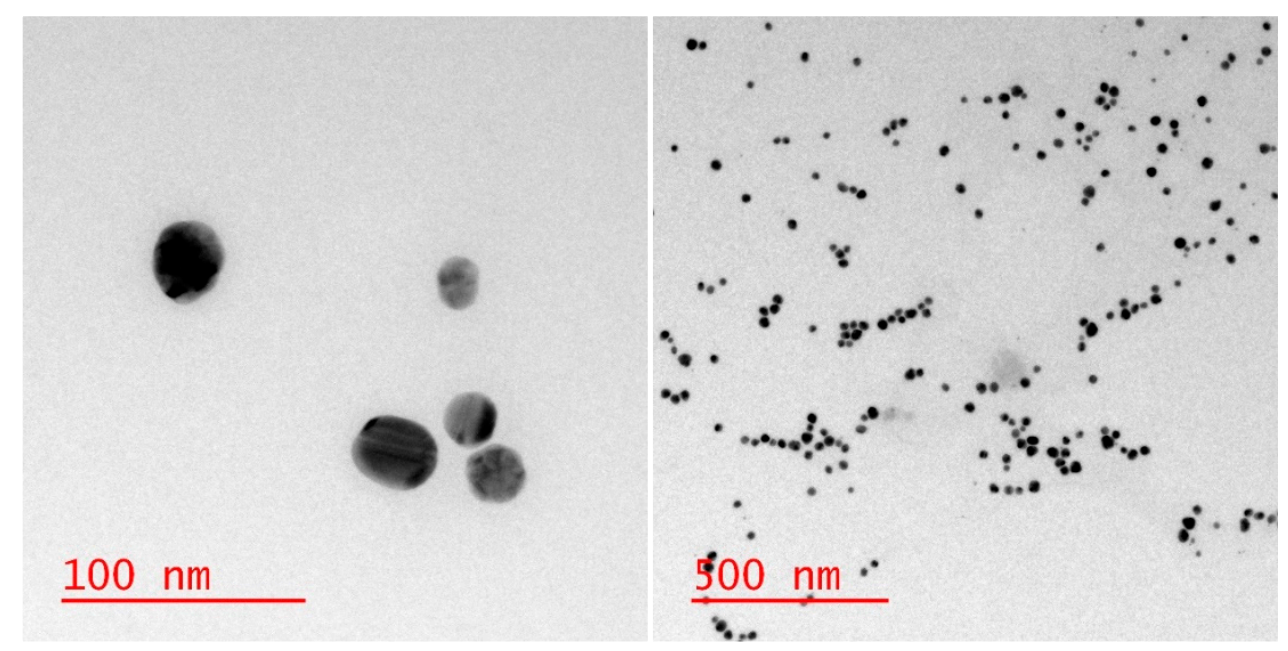

Figure 2. TEM images of $25 \mathrm{~nm}$ pristine AgNPs from Nanocomposix in double deionized water $\left(\mathrm{ddH}_{2} \mathrm{O}\right)$. Left: Close up view showing particles of mostly spherical shape. Right: A full view of the nanoparticle sample, indicating a reasonably monodisperse sample with little to no aggregation.

\subsection{Preparing Socks for In-Situ Impregnation (Kier boiling)}

Kier boiling of the commercial socks was employed to remove the wax finishing and non-cellulosic materials on the cotton fibers [46]. In brief, $14.7 \mathrm{~g}$ of $\mathrm{Na}_{2} \mathrm{CO}_{3}$ and 33.3 grams of $\mathrm{NaOH}$ were added to $1 \mathrm{~L}$ of $\mathrm{ddH}_{2} \mathrm{O}$ in a $2 \mathrm{~L}$ round bottom flask. A pair of white Hanes socks was added to the solution and refluxed for $10 \mathrm{~h}$. The solution turned yellow when boiling and eventually turned brown, indicating the removal of waxy and non-cellulosic material [46]. The socks were then rinsed five times in a $20 \%$ bleach solution and left to air dry.

\subsection{In-Situ Impregnation of Ag Nanoparticles into Socks (Laboratory-Prepared Socks)}

A kier boiled sock was immersed in $1 \mathrm{mM} \mathrm{AgNO} 3$ solution in a 4 L beaker at 1:20 $(w / v)$ and then autoclaved for $15 \mathrm{~min}$ at $121^{\circ} \mathrm{C}$ and 15 psi. Thereafter, the solution was left to cool to room temperature [47]. The socks were then rinsed with $\mathrm{ddH}_{2} \mathrm{O}(3 \times 1000 \mathrm{~mL})$ to remove any free NPs and then air-dried. The socks turned from white to brown, indicating the deposition of AgNPs on the socks [47].

\subsection{Day-to-day Wear with Sweat, Bleach, and Detergent}

Each treatment comprised a single sock in a $1 \mathrm{~L}$ beaker with $750 \mathrm{ml}$ of one of three solutions mimicking typical product use. For the sweat solution, a $1.08 \% \mathrm{NaCl}, 0.12 \%$ lactic acid, and $0.13 \%$ urea solution was prepared $(\mathrm{pH}$ ) [34]. To mimic typical bleaching or laundering conditions, $10 \mathrm{~mL}$ of 
bleach in $750 \mathrm{~mL}$ of water (pH 11.3), and $6 \mathrm{~mL}$ of detergent in $750 \mathrm{~mL}$ of water $(\mathrm{pH}$ 8.6) were used, respectively [31]. The solutions were then agitated on an Innova 40 Incubator Shaker (Eppendorf Inc., Enfield, CT, USA) at 100 oscillations per minute at $37^{\circ} \mathrm{C}$ for $24 \mathrm{~h}$, to simulate multiple uses and wash cycles.

\subsection{Wastewater Exposure}

Raw wastewater was characterized (see Supporting Information, Table S1) and used the very same day unless indicated. Five microliters of the pristine NPs solution $(5 \mathrm{mg} / \mathrm{mL})$ was added to $2 \mathrm{~mL}$ of raw wastewater. The leachate from the bleach, detergent, and sweat solutions was each mixed separately with wastewater at a 1:1 ratio to make up a $2 \mathrm{~mL}$ solution. The mixtures were then vortexed on a Vortex-Genie 2, (Scientific Industries Inc., Bohemia, NY, USA) for 10 minutes, and then left for $24 \mathrm{~h}$ at $21^{\circ} \mathrm{C}$ before the TEM grids were prepared.

A $15 \mathrm{mg} / \mathrm{L}$ aqueous solution of 1,6-hexanedithiol and a $5 \mathrm{mg} / \mathrm{L}$ aqueous solution of ammonium hydroxide were also used as model sulfur-rich and nitrogen-rich solutions, respectively. Pristine NPs and leachate from the bleach, detergent, and sweat solutions were directly added to the sulfur or nitrogen solutions, vortexed for $10 \mathrm{~min}$ and left for $24 \mathrm{~h}$ at $21^{\circ} \mathrm{C}$.

\subsection{Sample Preparation for ICP-MS Analysis}

\subsubsection{Incineration}

A small pre-weighed piece of the sock ( 100 mg) was placed in a $10 \mathrm{ml}$ Pyrex beaker and placed into a TEMCO 1520 benchtop muffle furnace. The furnace was heated to $600{ }^{\circ} \mathrm{C}$ and left for $3 \mathrm{~h}$ or until the sample turned to white ash. The sample was let to cool to room temperature before removing from the furnace [34]. The ash was then dissolved in $100 \mu \mathrm{L} \mathrm{HNO}_{3}$ and diluted 10X with $\mathrm{ddH}_{2} \mathrm{O}$.

\subsubsection{Aqua-Regia}

A small pre-weighed piece of the sock $(\sim 100 \mathrm{mg})$ was soaked in 1:3 ratio of $\mathrm{HNO}_{3}$ and $\mathrm{HCl}$ for $1 \mathrm{~h}$ and then heated to $90^{\circ} \mathrm{C}$ for $2 \mathrm{~h}$ [48]. The sample was diluted $10 \mathrm{X}$ with $\mathrm{ddH}_{2} \mathrm{O}$ before analysis.

\subsection{3. $\mathrm{HNO}_{3} / \mathrm{H}_{2} \mathrm{O}_{2}$}

A small pre-weighed piece of the sock $(\sim 100 \mathrm{mg})$ was submerged in 1:1 ratio of $\mathrm{HNO}_{3}$ and $\mathrm{H}_{2} \mathrm{O}$. The solution was heated to $100{ }^{\circ} \mathrm{C}$, and more $\mathrm{HNO}_{3}$ was added slowly until most of the sock dissolved. The solution was allowed to cool, and $30 \% \mathrm{H}_{2} \mathrm{O}_{2}$ was added until the bubbling stopped [31]. The sample was diluted $10 \times$ with $\mathrm{ddH}_{2} \mathrm{O}$ before analysis.

\subsection{Analysis}

ICP-MS was performed on an Agilent 8800QQQ (Agilent, Santa Clara, CA, USA) or an Agilent 7700x ICP-MS (Agilent, Santa Clara, CA, USA) (the latter used only to determine the best extraction method). The ICP-MS samples for the socks were prepared by dissolving the ash after incineration in

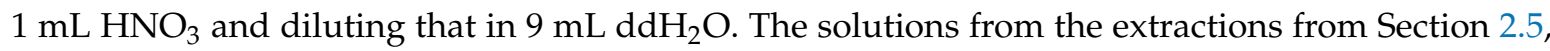
leachates, and wastewater incubations were used as-is. Appropriate dilutions were made to ensure the Ag concentration was within the calibration curve, and the results were normalized to compare the extraction methods.

The TEM images were taken using FEI Tecnai G2 TEM (Thermo Fisher Scientific, Waltham, MA, USA) at $200 \mathrm{kV}$. Samples were first prepared the same way as for the ICP-MS. The solutions were then vortexed for two minutes, and thereafter, $6 \mu \mathrm{L}$ of sample was placed on the grid and left for a minute. Residual liquid was removed using a pipette, and another $6 \mu \mathrm{L}$ of sample was added. The residual sample was removed for the second time, and the grid was left to air dry for $2 \mathrm{~h}$. The CF300-Cu grid was used. 
The EDS of the sample was taken through an attachment to the TEM, Aztec EDS from Oxford X-ray detection systems (Oxford Instruments, Tubney Woods, Abingdon, UK). The beam was made to top focus directly on the nanoparticle.

The XPS were taken using Kratos analytical model Axis Ultra DLD using $\mathrm{AlK}_{\alpha}$ radiation, charge neutralizer, and a delay-line detector (DLD) (Kratos Analytical Ltd, Wharfside, Manchester, UK). The samples used for XPS were all in the liquid form wherein $10 \mu \mathrm{L}$ of the sample was applied onto a glass coverslip. The sample was left to air dry for $2 \mathrm{~h}$. Once dried, another $10 \mu \mathrm{L}$ of sample was applied to the exact same spot and again left to air dry for $2 \mathrm{~h}$. This step was repeated 10 times or more until a visible spot was observed on the glass coverslip.

\section{Results and Discussion}

The diagram in Figure 3 shows the experimental design and path taken in analyzing the transformations of AgNP from three different sources through different use scenarios. The sources of AgNPs studied were the commercial socks, laboratory-prepared AgNP socks (in-situ NP synthesis used in industry $[49,50])$ and pristine AgNPs.

AgNPs Sources

Wastewater exposure
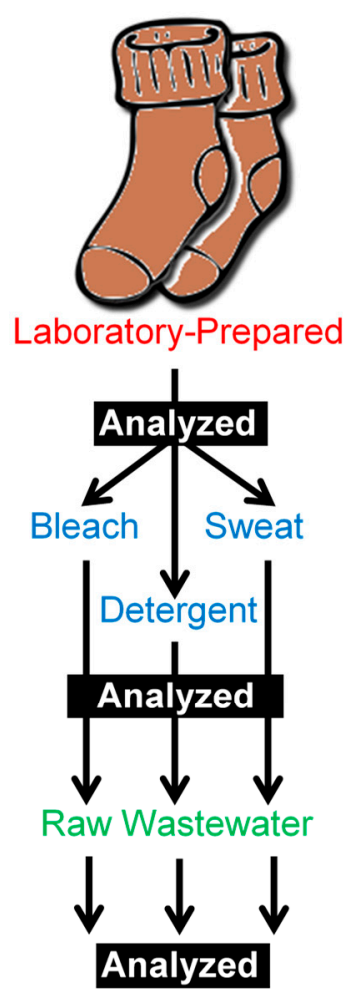

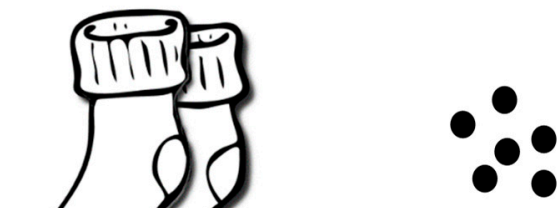

Pristine NPs
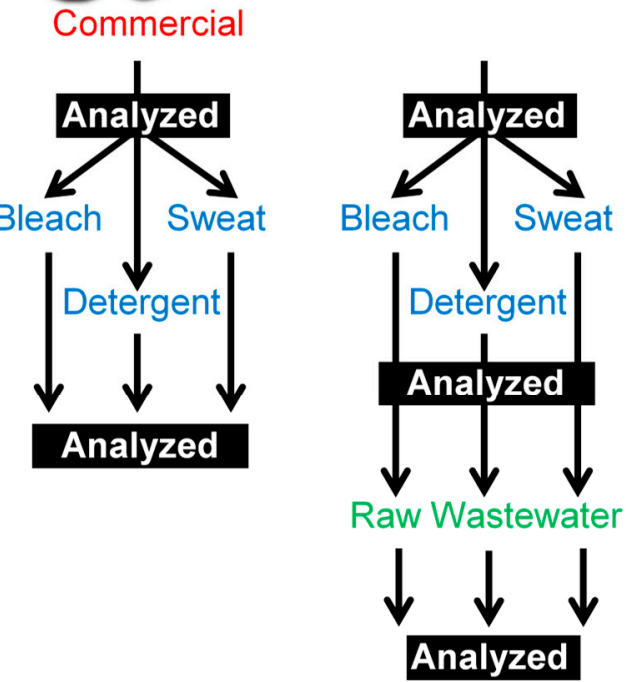

Figure 3. Summary of the lifecycle path and analysis of different AgNP sources studied in this paper. All analyses consist of TEM, EDS, and ICP-MS. The commercial socks were only analyzed through ICP-MS.

However, to analyze the silver content in these socks, either prior to and subsequent to use and wastewater exposure, a suitable method of extraction was required. Three methods (incineration, aqua-regia digestion, and nitric acid/hydrogen peroxide digestion) were selected, and the effectiveness of each technique was evaluated by ICP-MS results. The background Ag concentration of the instrument was measured to be $5 \mathrm{ng} / \mathrm{L}$ for the ICP-MS. Figure 4 shows the effectiveness of each preparation method in extracting Ag from the same commercial sock before day-to-day wear and wastewater exposure. Incinerating the socks yielded the most Ag extracted, confirmed by ANOVA statistical test ( $\mathrm{F}>\mathrm{F}$ crit, $\mathrm{P}=0.000294)$. As a result, incineration was selected as the preferred method of analysis and subsequently used to prepare the remainder of sock samples for analysis. 


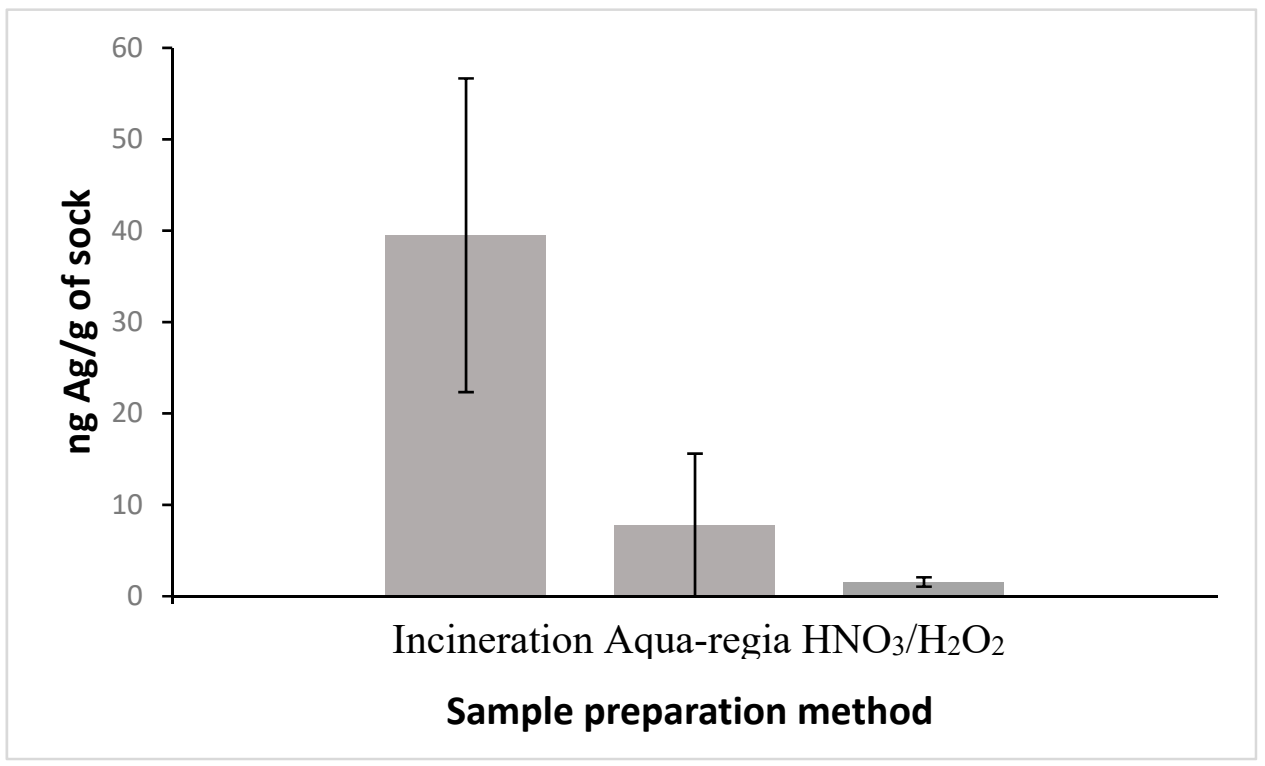

Figure 4. Mean ( \pm standard deviation) total Ag, derived from five samples, as measured through ICP-MS, based on different Ag extraction procedures on commercial socks before day-to-day use and wastewater exposure.

Transmission electron microscopy with Energy Dispersive X-ray Spectroscopy (TEM-EDS) was used throughout this study to confirm the presence of AgNPs and to note morphological and compositional changes. However, despite being able to quantify Ag in these textiles by ICP-MS, the AgNPs could not be found in the commercial socks through TEM and EDS analysis, as shown in Figure 5. The NPs found in the TEM images of commercial socks were determined to be a majority of $\mathrm{TiO}_{2} \mathrm{NPs}$. $\mathrm{TiO}_{2} \mathrm{NPs}$ can also be added as a white pigment within fabrics to mask the brown color of AgNP [51]. The overwhelming presence of $\mathrm{TiO}_{2}$ may have masked the ability to detect Ag through TEM-EDS. In contrast, the AgNPs could readily be observed in the laboratory-prepared socks with a size distribution of between 5 to $50 \mathrm{~nm}$ via TEM-EDS. The laboratory-prepared socks were brown as no $\mathrm{TiO}_{2}$ oxide was used to mask the color.

The Ag-containing socks (commercial and laboratory-prepared socks) were then analyzed for Ag content through ICP-MS, and the results are shown in Table 1. The Ag content of the laboratory-prepared sock was about $5000 \times$ higher than that of the commercial socks. This low Ag content in the commercial socks was below the detection limit for TEM-EDS. However, the concentration of Ag in the commercial sock is consistent with what has been reported in the literature; 2-1360 $\mu \mathrm{g}-\mathrm{Ag} / \mathrm{g}$-socks was detected when analyzing five different Ag-containing commercial socks [31]. Further analysis of the commercial socks was only done by ICP-MS as the detection of Ag in the commercial socks was not possible via TEM-EDS. 


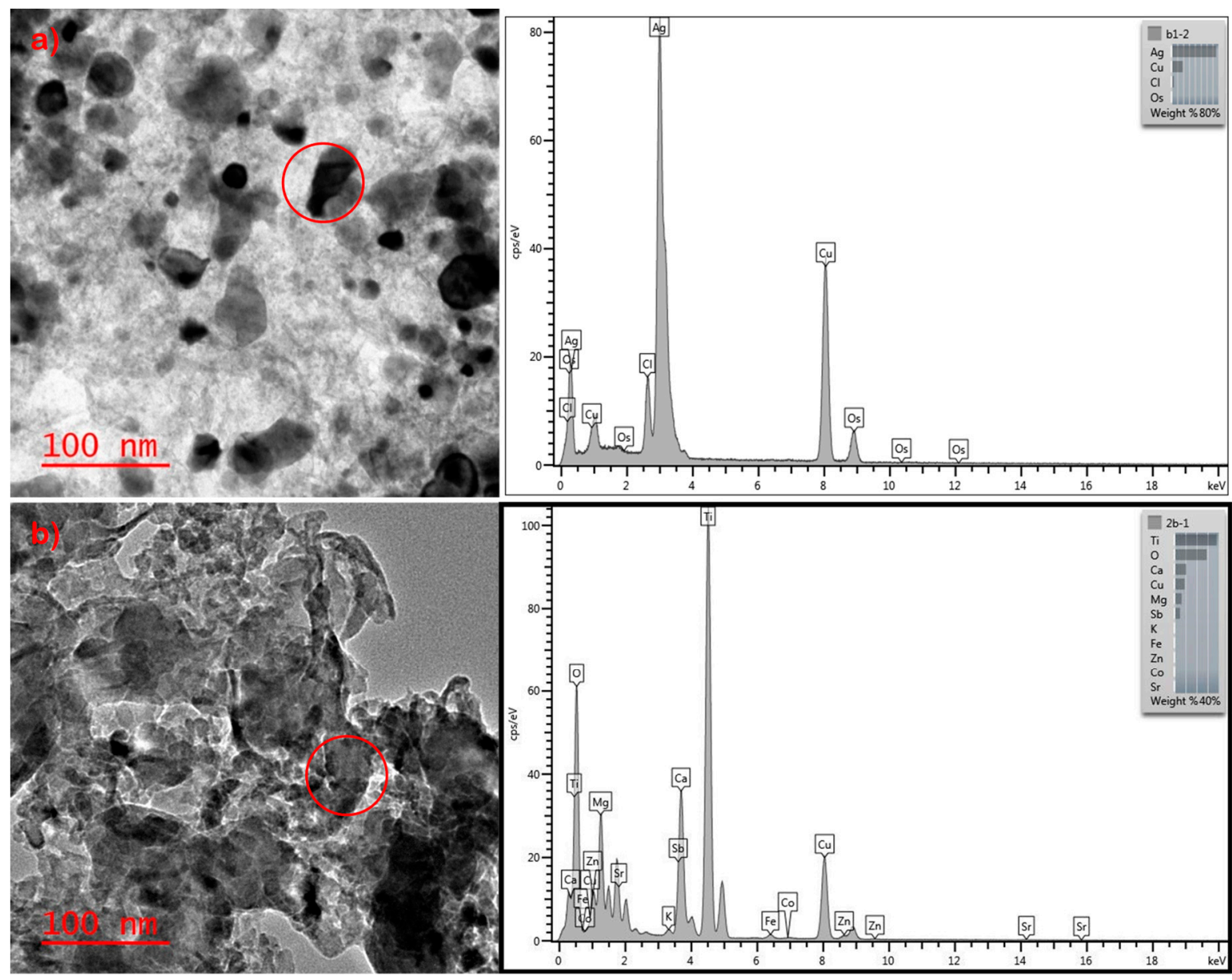

Figure 5. TEM and EDS image of (a) AgNPs found in laboratory-prepared socks (b) Only $\mathrm{TiO}_{2}$ and $\mathrm{ZnO}$ NPs found in commercial socks.

Table 1. ICP-MS result of Ag content in silver nanoparticle (AgNP) containing socks before any use or wastewater exposure.

\begin{tabular}{cc}
\hline Sample & mg/g of Sock \\
\hline Commercial socks & $0.0063 \pm 0.0040$ \\
Laboratory-prepared socks & $2.84 \pm 0.47$ \\
\hline
\end{tabular}

Three systems were evaluated through simulated day-to-day use conditions (sweating, washing, and bleaching): the commercial and laboratory-prepared socks, as well as free, pristine AgNPs (Figure 3). Human sweat varies in its $\mathrm{pH}$ and composition from different individuals. Kulthong et al. (2010) evaluated the effect of artificial sweat of different $\mathrm{pH}$ ranges on both laboratory-prepared and commercial fabrics and determined that a $\mathrm{pH}$ of 6.5 released the most amount of AgNPs [34]. A similar synthetic sweat composition was, therefore, used in this study [34]. Commercial detergent and bleach were also used in the present study, and concentrations followed that prescribed for use by the commercial products to mimic realistic washing and bleaching conditions. The $\mathrm{pH}$ of the bleach, detergent, and sweat solution were 11.3, 8.6, and 2.8, respectively. Another study had shown $\mathrm{pH}$ to not affect the chemical properties of AgNPs [52]. Exposing AgNPs to solutions of $\mathrm{pH} 2$ to 10 did not change the zeta potential of the nanoparticles [52].

The commercial and laboratory-prepared socks were incubated with bleach, detergent, and sweat solutions for $24 \mathrm{~h}$ to mimic day-to-day wear. These solutions were then analyzed using ICP-MS, of which results are shown in Table 2. Both the detergent and sweat solution had extracted Ag from the commercial socks, but there was no significant Ag in the bleach solution. The absence of Ag in the 
bleach solution could be due to the higher $\mathrm{pH}$ of the solution, limiting the extraction of Ag from the cotton fibers, or the extracted NPs could have agglomerated and settled leading to an inhomogeneous sample for ICP-MS. Such large agglomerated Ag particles caused by the bleach solution were observed in TEM images of samples (Figures 6 and 7). The observed agglomeration of Ag can be due to the oxidative dissolution of AgNPs, followed by the precipitation of $\mathrm{AgCl}$ [25].

Table 2. Mean concentration ( \pm standard deviation), derived from triplicates, as measured through ICP-MS for Ag extracted from socks into the solution due to day-to-day use.

\begin{tabular}{cccc}
\hline & \multicolumn{3}{c}{ Ag Concentration } \\
\hline Day-To-Day Use & Sweat & Bleach & Detergent \\
\hline Commercial socks $(\mathrm{ng} / \mathrm{L})( \pm 5 \mathrm{ng} / \mathrm{L})$ & 202 & 5 & 158 \\
\hline Laboratory-prepared socks $(\mathrm{mg} / \mathrm{L})( \pm 10 \mathrm{mg} / \mathrm{L})$ & 441 & 564 & 620 \\
\hline
\end{tabular}
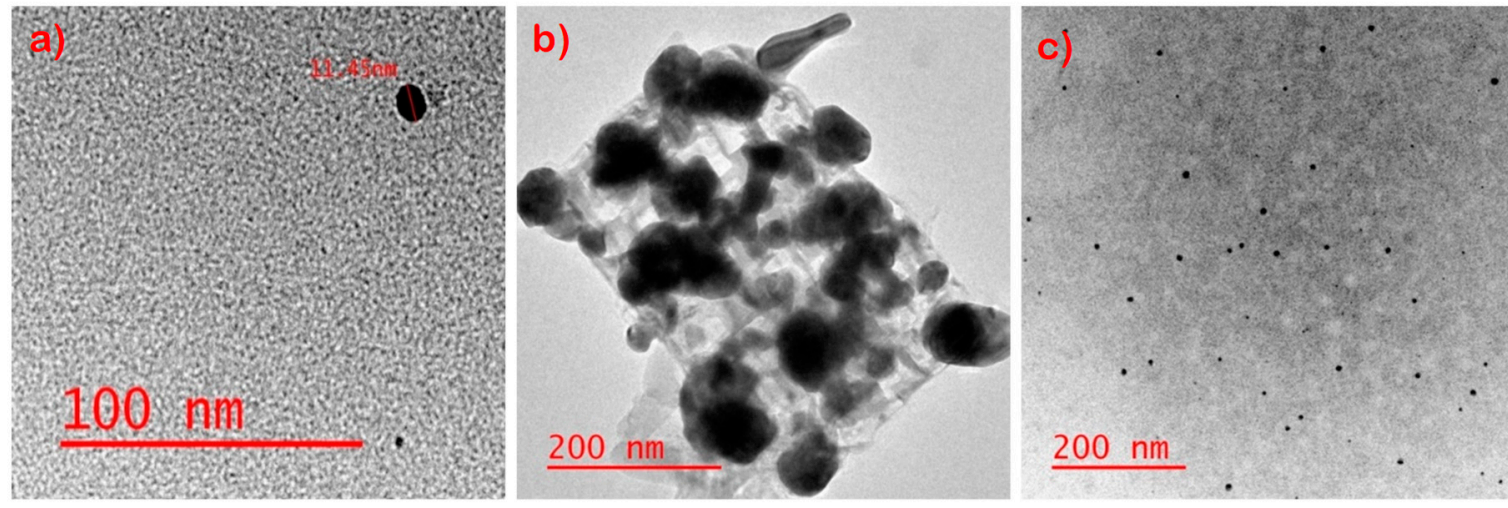

d)
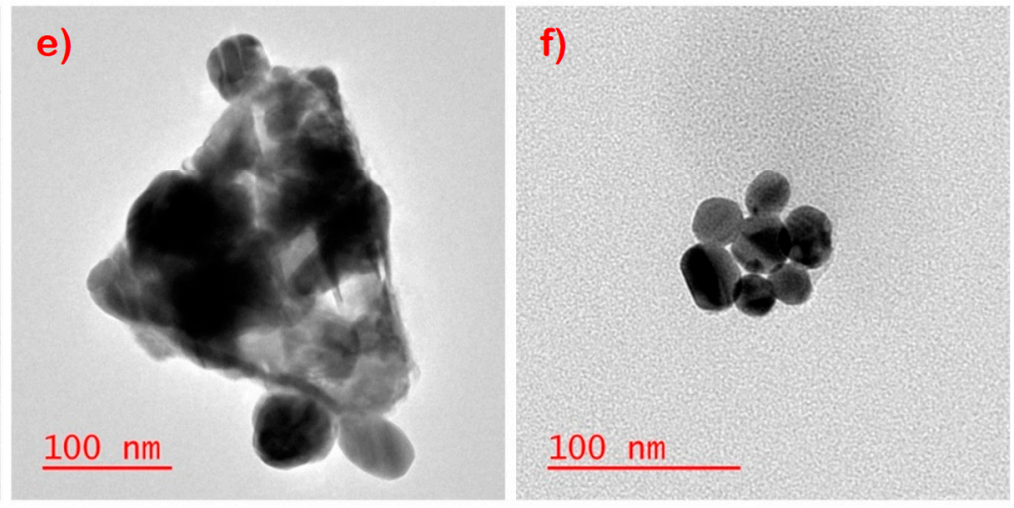

Figure 6. Representative TEM images of laboratory-prepared socks weathered with of (a) sweat, (b) bleach, (c) detergent and TEM images of pristine NPs weathered with (d) sweat, (e) bleach, and (f) detergent. See Supplementary Materials Figures S1 and S2 for EDS data.

Since the initial concentrations of Ag were low, TEM images were not taken for any of the solutions from the commercial socks. The laboratory-prepared socks had much more silver extracted into solution. However, the ratio of Ag released compared to the total Ag content in the socks was similar between the commercial and laboratory-prepared socks, indicative that the binding strength between the AgNPs and the cotton fibers in the lab-prepared socks resembled the commercial socks. Having similar nanoparticle release ratio makes the laboratory prepared socks a suitable model to yield an accurate representation of the commercial socks for day-to-day use and wastewater exposure.

Selected TEM images of the extracts from the laboratory-prepared socks sample exposed to bleach, detergent, and sweat conditions are shown in Figure 6a-c. Apart from the bleach solution, the AgNPs are seen to remain well-dispersed in the extracted solutions. The bleach solutions showed aggregated 
assemblies, appearing to be nucleated on salt crystals. EDS indicated the association of $\mathrm{S}$ and $\mathrm{Cl}$ with AgNPs in the sweat and detergent extracts, while only $\mathrm{Cl}$ could be co-detected with Ag in the bleach extracts.
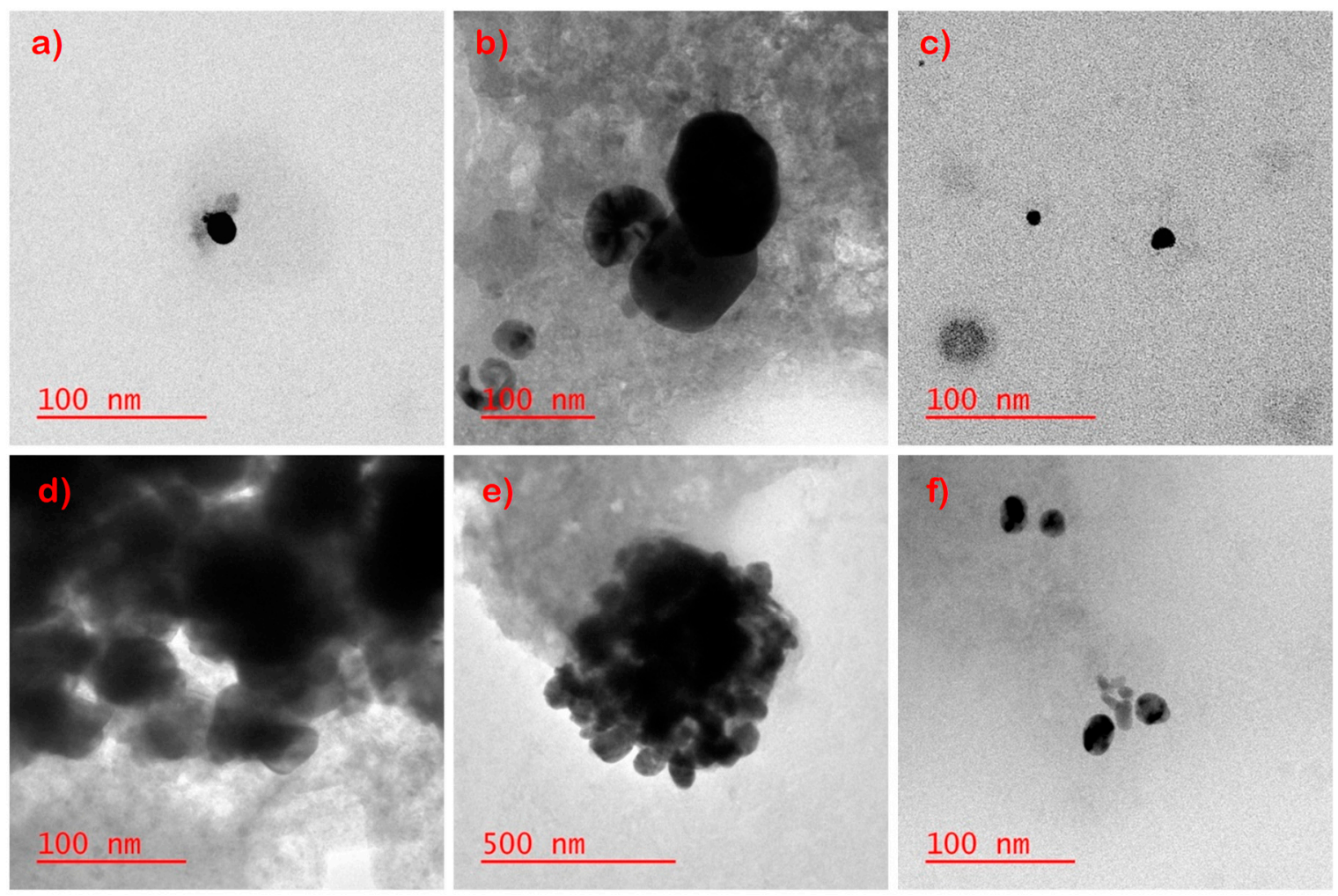

Figure 7. Representative TEM images of (a) sweat, (b) bleach, (c) detergent solution from laboratory-prepared socks and TEM images of (d) sweat, (e) bleach, (f) detergent solution from pristine NPs after 24-hour incubation with wastewater. See Supplementary Materials Figures S3 and S4 for EDS data.

For comparison, pristine NPs were put through the same conditions as the laboratory-prepared socks (Figure $6 \mathrm{~d}-\mathrm{f})$. In the sweat solution, the AgNP were mostly well dispersed, and some association on $\mathrm{NaCl}$ salt crystals was observed. The AgNPs extracted from the bleach solution appeared to once again to be aggregated, and $\mathrm{Cl}$ could be co-detected by EDS. Finally, in detergent, small aggregates could be observed with only $\mathrm{S}$ co-detected. The pristine AgNPs show a similar transformation as the AgNPs that leach out of the laboratory-prepared socks (Figure 6a-c).

AgNPs extracted from a textile by sweat, bleach, or detergent could find their way into the wastewater collection system by bathing of the user or washing of the textile. It is estimated that wastewater travels within the collection system for a United States' national average of $3.3 \mathrm{~h}$ up to as long as $15 \mathrm{~h}$ in larger cities before reaching the wastewater treatment facility [53]. During this time, the NPs will be exposed to organic matter, nitrogen, phosphorus, sulfur, metals, and a wide range of chemical compounds and microorganisms. The chemical and microbial reactions, dissolved oxygen concentration, oxidation-reduction potential, ionic strength, and $\mathrm{pH}$ of wastewater will change as a function of residence time in the sewer, which can physically and chemically transform the AgNPs. The effect of incubation in raw wastewater was compared for the AgNPs that had been extracted through the various use-scenarios, as well as pristine NPs, to observe the effects on morphology or composition.

The solutions obtained from bleach, detergent, and sweat extraction of laboratory-prepared socks were added 1:1 to wastewater to observe the effects on the AgNPs. (Figure 7). With the bleach solution, the AgNPs agglomerated as their average diameter increased from 5 to $50 \mathrm{~nm}$ to $>100 \mathrm{~nm}$. In contrast, 
the particle sizes detected from the detergent and sweat solutions post-wastewater incubation did not show an increase of particle size. However, halos with high $\mathrm{S}$ and $\mathrm{Cl}$ content could be observed around the dispersed particles suggesting a respective association with $\mathrm{Ag}$ and potentially dissolution and re-precipitation.

The solutions obtained from bleach, detergent, and sweat of pristine NPs were also examined after a $24 \mathrm{~h}$ incubation in wastewater (Figure 7). Larger aggregates and agglomerates with low levels of $\mathrm{Cl}$ content could once again be observed in the bleach sample. NPs in the sweat solution appeared to be similar to those in the bleach solution. The detergent samples appeared more dispersed, and significant association with $\mathrm{Cl}$ and $\mathrm{S}$ was observed.

To have a better understanding of the effect of wastewater composition on AgNP morphology and composition, pristine AgNPs that had not undergone any pretreatment were introduced to the wastewater, as well as sulfur-rich and nitrogen-rich solutions, and 1:1 wastewater/sulfur solution and wastewater/nitrogen solutions (Supplementary Materials Figure S5). Pristine AgNPs incubated in wastewater became aggregated, and sulfur-rich halos were observed around the particles. The introduction of the AgNPs to the model sulfur-rich solutions showed similar morphology effects to that observed with wastewater, while exposure to our nitrogen-rich solution did not lead to aggregation or show formations of halos. The detection of nitrogen could be because of ammonia forming a stable ligand with $\mathrm{Ag}, \mathrm{Ag}\left(\mathrm{NH}_{3}\right)_{2}^{+}$which is stabilized by the $\mathrm{OH}^{-}$ions in solution [54]. Similar results were observed by adding pristine NPs to mixtures of wastewater + sulfur-rich solution and wastewater + nitrogen-rich solution. The effects of different wastewater $\mathrm{pH}(4.0,6.0$, and 8.0) were also tested (Supplementary Materials Figure S6). The change in $\mathrm{pH}$ did not affect the form or aggregation state of AgNPs. Pristine nanoparticles have been shown to start aggregating when the $\mathrm{pH}$ drops below pH 3.0 [52].

To further analyze these chemical changes, samples of pristine AgNPs incubated in wastewater were analyzed using XPS. In Figure 8, a shift in binding energy was observed for Ag when the nanoparticles were incubated with wastewater. The shift to higher binding energy is caused by the oxidation of the Ag atom [55]. The shift of the binding energy further supports the association of $S$ and $\mathrm{Cl}$ with AgNPs observed in EDS are due to the AgNPs going through a chemical transformation [56].

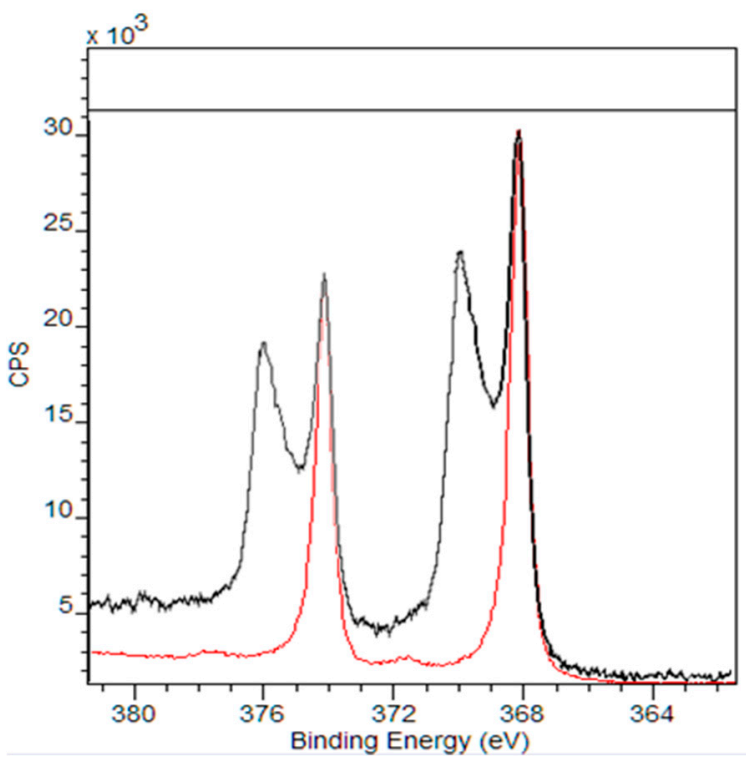

Figure 8. XPS spectra showing the binding energy of Ag of pristine AgNPs (red) and those incubated in wastewater (black) obtained through high-resolution XPS.

Table 3 below shows the summary based on all the TEM images and EDS data from the samples. The nanoparticles were observed to aggregate, agglomerate, and associate with chlorine and sulfur 
when exposed to wastewater, regardless of origin and previous weathering. Images shown in this paper were selected as being the best representation of the AgNPs on the $100 \mathrm{~nm}$ scale. Some agglomerations were observed to reach the micro scale, which supports the recent reports where pristine AgNP exposed to simulated detergent and bleach wash cycles form large agglomerates [33,57]. The elemental association with $\mathrm{Cl}$ and $\mathrm{S}$ observed with EDS is likely because of the formation of $\mathrm{AgCl}$ and $\mathrm{Ag}_{2} \mathrm{~S}$. A similar interpretation of the EDS data for AgNPs in simulated wash cycles had been reported in a recent study [35].

Table 3. Summary of the type of morphological changes and chemical associations of AgNPs when pristine or embedded into fabric, and applied to various use and exposure conditions.

\begin{tabular}{|c|c|c|c|c|}
\hline Samples & Conditions & & Changes & \\
\hline & & $\begin{array}{c}\text { Agglomeration } \\
{[23]}\end{array}$ & $\begin{array}{c}\text { Aggregation } \\
{[23]}\end{array}$ & $\begin{array}{c}\text { Elemental } \\
\text { Association }\end{array}$ \\
\hline \multirow{6}{*}{$\begin{array}{c}\text { Laboratory-prepared } \\
\text { Socks }\end{array}$} & Sweat & No & No & $\mathrm{Cl}, \mathrm{S}$ \\
\hline & Bleach & Yes & Yes & $\mathrm{Cl}$ \\
\hline & Detergent & No & No & $\mathrm{Cl}, \mathrm{S}$ \\
\hline & Sweat + Wastewater & Yes & Yes & $\mathrm{Cl}, \mathrm{S}$ \\
\hline & Bleach + Wastewater & Yes & Yes & $\mathrm{Cl}, \mathrm{S}$ \\
\hline & Detergent + Wastewater & Yes & Yes & $\mathrm{Cl}, \mathrm{S}$ \\
\hline \multirow{6}{*}{ Pristine Nanoparticles } & Sweat & No & Yes & $\mathrm{Cl}$ \\
\hline & Bleach & Yes & Yes & $\mathrm{Cl}$ \\
\hline & Detergent & No & Yes & $\mathrm{Cl}, \mathrm{S}$ \\
\hline & Sweat + Wastewater & Yes & Yes & $\mathrm{Cl}, \mathrm{S}$ \\
\hline & Bleach + Wastewater & Yes & Yes & $\mathrm{Cl}, \mathrm{S}$ \\
\hline & Detergent + Wastewater & Yes & Yes & $\mathrm{Cl}, \mathrm{S}$ \\
\hline
\end{tabular}

However, not all the nanoparticles imaged and analyzed appeared to have oxidized to $\mathrm{AgCl}$ and $\mathrm{Ag}_{2} \mathrm{~S}$. According to a previous study on introducing commercial AgNP fabric to the bleach and detergent, only 50\% of the AgNPs were converted to AgCl. [58] Since X-ray Absorption Near Edge Spectroscopy (XANES) was used for elemental analysis in that study, only the surface of the nanoparticles were analyzed for the presence of $\mathrm{AgCl}$. The percent $\mathrm{AgCl}$ would potentially be lower if the entire core of the nanoparticle was analyzed [59].

Despite the qualitative nature of this study, some important conclusions can be drawn about the transformations of AgNPs during these simulated day-to-day use and wastewater exposure processes. While AgNPs do not retain their pristine form from product incorporation through use scenarios, to travel in the wastewater collection stream, they are also not fully dissolved throughout these steps. Given that others have detected AgNPs in the wastewater influent and effluent as well as in sewage sludge, our use of these simulated scenarios represents the real-world scenarios of the nanoparticle life-cycle $[45,60]$. Furthermore, despite evidence for transformations throughout the use and exposure steps, the most dramatic changes to the nanoparticle morphology and composition appear to have occurred in our final step mimicking the time spent in the wastewater collection stream. As a result, using a 24-h wastewater incubation of pristine nanoparticles alone may be sufficient to prepare a more relevant model "weathered nanoparticle" sample that can be used for environmental studies seeking to inform future decision making. In future studies, further transformations on the weathered AgNPs through scenarios that mimic wastewater and biosolid treatment processes will be explored. 
Supplementary Materials: The following are available online at http://www.mdpi.com/2079-4991/9/9/1258/s1, Figure S1: TEM image and EDS data of extracted samples from laboratory-prepared socks exposed to (a) sweat, (b) bleach, and (c) detergent. Circles indicate areas probed for EDS, Figure S2: TEM image and EDS data of pristine NPs weathered with (a) sweat, (b) bleach, and (c) detergent. Circles indicate areas probed for EDS, Figure S3: TEM image and EDS data of extracted samples from (a) sweat, (b) bleach, and (c) detergent solutions after treatment with wastewater. Circles indicate areas probed for EDS, Figure S4: TEM image and EDS data of pristine NPs treated with wastewater after weathering with (a) sweat, (b) bleach, and (c) detergent. Circles indicate areas probed for EDS, Figure S5: TEM image and EDS data of pristine AgNPs in (a) wastewater, (b) sulfur-rich solution, (c) nitrogen-rich solution, (d) wastewater + sulfur-rich solution, and $€$ wastewater + nitrogen-rich solution. Circles indicate areas probed for EDS, Figure S6: TEM image and EDS data of pristine AgNPs in wastewater with $\mathrm{pH}$ altered to (a) $\mathrm{pH} 4.0$, (b) $\mathrm{pH}$ 6.0, and (c) $\mathrm{pH}$ 8.0. Circles indicate areas probed for EDS, Table S1: The test results for raw wastewater composition. Sample 1 of raw wastewater was used for the pristine NPs. Sample 2 of raw wastewater was used for the solutions from day-to-day wear of laboratory-prepared socks and pristine NPs.

Author Contributions: S.M., J.P., B.O., and M.C.D. conceived of the project. S.M. performed the experiments, S.M., B.O., and M.C.D. analyzed the data, S.M. drafted the manuscript and J.P., B.O., and M.C.D. edited the manuscript. All authors provided critical feedback and helped shape the research, analysis, and manuscript.

Funding: This research was funding by an Environment and Climate Change Canada (ECCC) Grants and Contribution Agreement and by the Natural Sciences and Engineering Research Council of Canada (NSERC).

Acknowledgments: M.C.D. and B.O. acknowledge Environment and Climate Change Canada for a Grants and Contributions Agreement to support this research. This work would not be possible without the technical help of Jianqun Wang, the TEM and SEM facility manager in obtaining TEM images and troubleshooting the instrument. We would like to thank Nimal DeSilva for his assistance in ICP-MS analysis of our sample.

Conflicts of Interest: The authors declare no conflict of interest.

\section{References}

1. Zhang, Z.; Lin, P.-C. Noble metal nanoparticles: Synthesis, and biomedical implementations. In Emerging Applications of Nanoparticles and Architecture Nanostructures; Elsevier Inc.: Amsterdam, The Netherlands, 2018; pp. 177-233.

2. Cassano, D.; David, J.; Luin, S.; Voliani, V. Passion fruit-like nano-architectures: A general synthesis route. Sci. Rep. 2017, 7, 43795. [CrossRef]

3. The Project on Emerging Nanotechnologies. Available online: http://www.nanotechproject.org/cpi/about/ analysis/ (accessed on 1 April 2015).

4. Vance, M.E.; Kuiken, T.; Vejerano, E.P.; McGinnis, S.P.; Hochella, M.F.; Rejeski, D.; Hull, M.S. Nanotechnology in the real world: Redeveloping the nanomaterial consumer products inventory. Beilstein J. Nanotechnol. 2015, 6, 1769-1780. [CrossRef]

5. Walser, T.; Demou, E.; Lang, D.J.; Hellweg, S. Prospective environmental life cycle assessment of nanosilver T-shirts. Environ. Sci. Technol. 2011, 45, 4570-4578. [CrossRef]

6. Colman, B.P.; Arnaout, C.L.; Anciaux, S.; Gunsch, C.K.; Hochella, M.F.; Kim, B.; Lowry, G.V.; McGill, B.M.; Reinsch, B.C.; Richardson, C.J.; et al. Low Concentrations of Silver Nanoparticles in Biosolids Cause Adverse Ecosystem Responses under Realistic Field Scenario. PLoS ONE 2013, 8, e57189. [CrossRef]

7. Panyala, N.R.; Peña-Méndez, E.M.; Havel, J. Silver or silver nanoparticles: A hazardous threat to the environment and human health? J. Appl. Biomed. 2008, 6, 117-129. [CrossRef]

8. Miseljic, M.; Olsen, S.I. Life-cycle assessment of engineered nanomaterials: A literature review of assessment status. J. Nanoparticle Res. 2014, 16, 2427. [CrossRef]

9. Diez-Ortiz, M.; Lahive, E.; George, S.; Ter Schure, A.; Van Gestel, C.A.M.; Jurkschat, K.; Svendsen, C.; Spurgeon, D.J. Short-term soil bioassays may not reveal the full toxicity potential for nanomaterials; bioavailability and toxicity of silver ions (AgNO3) and silver nanoparticles to earthworm Eisenia fetida in long-term aged soils. Environ. Pollut. 2015, 203, 191-198. [CrossRef]

10. Fernández, M.D.; Alonso-Blázquez, M.N.; García-Gómez, C.; Babin, M. Evaluation of zinc oxide nanoparticle toxicity in sludge products applied to agricultural soil using multispecies soil systems. Sci. Total Environ. 2014, 497-498, 688-696. [CrossRef]

11. Fabrega, J.; Fawcett, S.R.; Renshaw, J.C.; Lead, J.R. Silver nanoparticle impact on bacterial growth: Effect of $\mathrm{pH}$, concentration, and organic matter. Environ. Sci. Technol. 2009, 43, 7285-7290. [CrossRef]

12. Gao, J.; Lin, L.; Wei, A.; Sepúlveda, M.S. Protein Corona Analysis of Silver Nanoparticles Exposed to Fish Plasma. Environ. Sci. Technol. Lett. 2017, 4, 174-179. [CrossRef] 
13. Shukla, S.; Seal, S.; Mishra, S.R. Synthesis and Characterization of Silver Sulfide Nanoparticles Containing Sol-Gel Derived HPC-Silica Film for Ion-Selective Electrode Application. J. Sol-Gel Sci. Technol. 2002, 23, 151-164. [CrossRef]

14. Kim, D.; Kwon, S.-J.; Wu, X.; Sauve, J.; Lee, I.; Nam, J.; Kim, J.; Dordick, J.S. Selective Killing of Pathogenic Bacteria by Antimicrobial Silver Nanoparticle-Cell Wall Binding Domain Conjugates. ACS Appl. Mater. Interfaces 2018, 10, 13317-13324. [CrossRef]

15. Navarro, E.; Piccapietra, F.; Wagner, B.; Marconi, F.; Kaegi, R.; Odzak, N.; Sigg, L.; Behra, R. Toxicity of silver nanoparticles to Chlamydomonas reinhardtii. Environ. Sci. Technol. 2008, 42, 8959-8964. [CrossRef]

16. Fabrega, J.; Luoma, S.N.; Tyler, C.R.; Galloway, T.S.; Lead, J.R. Silver nanoparticles: Behaviour and effects in the aquatic environment. Environ. Int. 2011, 37, 517-531. [CrossRef]

17. Laban, G.; Nies, L.F.; Turco, R.F.; Bickham, J.W.; Sepúlveda, M.S. The effects of silver nanoparticles on fathead minnow (Pimephales promelas) embryos. Ecotoxicology 2010, 19, 185-195. [CrossRef]

18. Dhas, S.P.; Shiny, P.J.; Khan, S.; Mukherjee, A.; Chandrasekaran, N. Toxic behavior of silver and zinc oxide nanoparticles on environmental microorganisms. J. Basic Microbiol. 2013, 916-927. [CrossRef]

19. Prabhu, S.; Poulose, E.K. Silver nanoparticles: Mechanism of antimicrobial action, synthesis, medical applications, and toxicity effects. Int. Nano Lett. 2012, 2, 32. [CrossRef]

20. Marambio-Jones, C.; Hoek, E.M.V. A review of the antibacterial effects of silver nanomaterials and potential implications for human health and the environment. J. Nanoparticle Res. 2010, 12, 1531-1551. [CrossRef]

21. El-Shishtawy, R.M.; Asiri, A.M.; Abdelwahed, N.A.M.; Al-Otaibi, M.M. In situ production of silver nanoparticle on cotton fabric and its antimicrobial evaluation. Cellulose 2011, 18, 75-82. [CrossRef]

22. Servin, A.D.; White, J.C. Nanotechnology in agriculture: Next steps for understanding engineered nanoparticle exposure and risk. NanoImpact 2016, 1, 9-12. [CrossRef]

23. Nichols, G.; Byard, S.; Bloxham, M.J.; Botterill, J.; Dawson, N.J.; Dennis, A.; Diart, V.; North, N.C.; Sherwood, J.D. A review of the terms agglomerate and aggregate with a recommendation for nomenclature used in powder and particle characterization. J. Pharm. Sci. 2002, 91, 2103-2109. [CrossRef]

24. Mitrano, D.M.; Rimmele, E.; Wichser, A.; Erni, R.; Height, M.; Nowack, B. Presence of nanoparticles in wash water from conventional silver and nano-silver textiles. ACS Nano 2014, 8, 7208-7219. [CrossRef]

25. Garg, S.; Rong, H.; Miller, C.J.; Waite, T.D. Oxidative Dissolution of Silver Nanoparticles by Chlorine: Implications to Silver Nanoparticle Fate and Toxicity. Environ. Sci. Technol. 2016, 50, 3890-3896. [CrossRef]

26. Meier, C.; Voegelin, A.; Pradas Del Real, A.; Sarret, G.; Mueller, C.R.; Kaegi, R. Transformation of Silver Nanoparticles in Sewage Sludge during Incineration. Environ. Sci. Technol. 2016, 50, 3503-3510. [CrossRef]

27. Dale, A.L.; Lowry, G.V.; Casman, E.A. Modeling nanosilver transformations in freshwater sediments. Environ. Sci. Technol. 2013, 47, 12920-12928. [CrossRef]

28. Chambers, B.A.; Afrooz, A.R.M.N.; Bae, S.; Aich, N.; Katz, L.; Saleh, N.B.; Kirisits, M.J. Effects of chloride and ionic strength on physical morphology, dissolution, and bacterial toxicity of silver nanoparticles. Environ. Sci. Technol. 2014, 48, 761-769. [CrossRef]

29. Liu, J.; Wang, Z.; Liu, F.D.; Kane, A.B.; Hurt, R.H. Chemical transformations of nanosilver in biological environments. ACS Nano 2012, 6, 9887-9899. [CrossRef]

30. Nowack, B.; Ranville, J.F.; Diamond, S.; Gallego-Urrea, J.A.; Metcalfe, C.; Rose, J.; Horne, N.; Koelmans, A.A.; Klaine, S.J. Potential scenarios for nanomaterial release and subsequent alteration in the environment. Environ. Toxicol. Chem. 2012, 31, 50-59. [CrossRef]

31. Benn, T.M.; Westerhoff, P. Nanoparticle silver released into water from commercially available sock fabrics. Environ. Sci. Technol. 2008, 42, 4133-4139. [CrossRef]

32. Mitrano, D.M.; Lombi, E.; Dasilva, Y.A.R.; Nowack, B. Unraveling the Complexity in the Aging of Nanoenhanced Textiles: A Comprehensive Sequential Study on the Effects of Sunlight and Washing on Silver Nanoparticles. Environ. Sci. Technol. 2016, 50, 5790-5799. [CrossRef]

33. Hedberg, J.; Skoglund, S.; Karlsson, M.E.; Wold, S.; Odnevall Wallinder, I.; Hedberg, Y. Sequential studies of silver released from silver nanoparticles in aqueous media simulating sweat, laundry detergent solutions and surface water. Environ. Sci. Technol. 2014, 48, 7314-7322. [CrossRef]

34. Kulthong, K.; Srisung, S.; Boonpavanitchakul, K.; Kangwansupamonkon, W.; Maniratanachote, R. Determination of silver nanoparticle release from antibacterial fabrics into artificial sweat. Part Fibre Toxicol. 2010, 7, 8. [CrossRef] 
35. Lorenz, C.; Windler, L.; von Goetz, N.; Lehmann, R.P.; Schuppler, M.; Hungerbühler, K.; Heuberger, M.; Nowack, B. Characterization of silver release from commercially available functional (nano)textiles. Chemosphere 2012, 89, 817-824. [CrossRef]

36. Brar, S.K.; Verma, M.; Tyagi, R.D.; Surampalli, R.Y. Engineered nanoparticles in wastewater and wastewater sludge-Evidence and impacts. Waste Manag. 2010, 30, 504-520. [CrossRef]

37. Sheng, Z.; Liu, Y. Effects of silver nanoparticles on wastewater biofilms. Water Res. 2011, 45, 6039-6050. [CrossRef]

38. Hou, L.; Li, K.; Ding, Y.; Li, Y.; Chen, J.; Wu, X.; Li, X. Removal of silver nanoparticles in simulated wastewater treatment processes and its impact on COD and NH 4 reduction. Chemosphere 2012, 87, 248-252. [CrossRef]

39. García, A.; Delgado, L.; Torà, J.A.; Casals, E.; González, E.; Puntes, V.; Font, X.; Carrera, J.; Sánchez, A. Effect of cerium dioxide, titanium dioxide, silver, and gold nanoparticles on the activity of microbial communities intended in wastewater treatment. J. Hazard. Mater. 2012, 199-200, 64-72. [CrossRef]

40. Kaegi, R.; Sinnet, B.; Zuleeg, S.; Hagendorfer, H.; Mueller, E.; Vonbank, R.; Boller, M.; Burkhardt, M. Release of silver nanoparticles from outdoor facades. Environ. Pollut. 2010, 158, 2900-2905. [CrossRef]

41. Kaiser, J.P.; Roesslein, M.; Diener, L.; Wick, P. Human health risk of ingested nanoparticles that are added as multifunctional agents to paints: An in vitro study. PLOS ONE 2013, 8, e83215. [CrossRef]

42. Kaegi, R.; Voegelin, A.; Ort, C.; Sinnet, B.; Thalmann, B.; Krismer, J.; Hagendorfer, H.; Elumelu, M.; Mueller, E. Fate and transformation of silver nanoparticles in urban wastewater systems. Water Res. 2013, 47, 3866-3877. [CrossRef]

43. Martin, L.; Kelso, G. Use of Biosolids in Agriculture. In Primefacts; NSW DPI: Sydney, Australia, 2009; Volume 859.

44. Kaegi, R.; Voegelin, A.; Sinnet, B.; Zuleeg, S.; Hagendorfer, H.; Burkhardt, M.; Siegrist, H. Behavior of metallic silver nanoparticles in a pilot wastewater treatment plant. Environ. Sci. Technol. 2011, 45, 3902-3908. [CrossRef]

45. Kim, B.; Park, C.S.; Murayama, M.; Hochella, M.F. Discovery and characterization of silver sulfide nanoparticles in final sewage sludge products. Environ. Sci. Technol. 2010, 44, 7509-7514. [CrossRef]

46. Karande, V.S.; Bharimalla, A.K.; Vigneshwaran, N.; Kadam, P.G.; Mhaske, S.T. Cotton linter nano-fibers as the potential reinforcing agent for guar gum. Iran. Polym. J. 2014, 23, 869-879. [CrossRef]

47. Vigneshwaran, N.; Kathe, A.; Varadarajan, P.; Nachane, R.; Balasubramanya, R. Functional Finishing of Cotton Fabrics Using Silver Nanoparticles. J. Nanosci. Nanotechnol. 2007, 7, 1893-1897. [CrossRef]

48. Mwilu, S.K.; Siska, E.; Baig, R.B.N.; Varma, R.S.; Heithmar, E.; Rogers, K.R. Separation and measurement of silver nanoparticles and silver ions using magnetic particles. Sci. Total Environ. 2014, 472, 316-323. [CrossRef]

49. Nanotex, L.L.C. Nanoparticle-Based Permanent Treatments for Textiles. U.S. Patent 6607994B2, 18 August 2003.

50. Geganken, A.; Nitzan, Y.; Perelshtein, I.; Perkas, N.; Applerot, G. Sonochemical Coating of Textiles with Metal Oxide Nanoparticles for Antimicrobial Fabrics. EP Patent 2294260A1, 16 March 2011.

51. Eastern Research Group. State of the Science Literature Review: Nano Titanium Dioxide Environmental Matters; U.S. Environmental Protection Agency: Washington, DC, USA, 2010.

52. Badawy, A.M.E.; Luxton, T.P.; Silva, R.G.; Scheckel, K.G.; Suidan, M.T.; Tolaymat, T.M. Impact of Environmental Conditions ( $\mathrm{pH}$, Ionic Strength, and Electrolyte Type) on the Surface Charge and Aggregation of Silver Nanoparticles Suspensions. Environ. Sci. Technol. 2010, 44, 1260-1266. [CrossRef]

53. Kapo, K.E.; Paschka, M.; Vamshi, R.; Sebasky, M.; McDonough, K. Estimation of U.S. sewer residence time distributions for national-scale risk assessment of down-the-drain chemicals. Sci. Total Environ. 2017, 603-604, 445-452. [CrossRef]

54. Fox, B.S.; Beyer, M.K.; Bondybey, V.E. Coordination chemistry of silver cations. J. Am. Chem. Soc. 2002, 124, 13613-13623. [CrossRef]

55. Hu, P.; Hou, D.; Huang, Y.; Hu, X.; Chen, C. Biomaterial-assisted synthesis of AgCl@Ag concave cubes with efficient visible-light-driven photocatalytic activity. CrystEngComm 2013, 16, 649-653. [CrossRef]

56. Kaushik, V.K. XPS core level spectra and Auger parameters for some silver compounds. J. Electron Spectros. Relat. Phenom. 1991, 56, 273-277. [CrossRef]

57. Geranio, L.; Heuberger, M.; Nowack, B. The behavior of silver nanotextiles during washing. Environ. Sci. Technol. 2009, 43, 8113-8118. [CrossRef] 
58. Impellitteri, C.A.; Tolaymat, T.M.; Scheckel, K.G. The Speciation of Silver Nanoparticles in Antimicrobial Fabric Before and After Exposure to a Hypochlorite/Detergent Solution. J. Environ. Qual. 2009, 38, 1528-1530. [CrossRef]

59. Hemraj-Benny, T.; Banerjee, S.; Sambasivan, S.; Balasubramanian, M.; Fischer, D.A.; Eres, G.; Puretzky, A.A.; Geohegan, D.B.; Lowndes, D.H.; Han, W.; et al. Near-Edge X-ray Absorption Fine Structure Spectroscopy as a Tool for Investigating Nanomaterials. Small 2006, 2, 26-35. [CrossRef]

60. Cervantes-Avilés, P.; Huang, Y.; Keller, A.A. Incidence and persistence of silver nanoparticles throughout the wastewater treatment process. Water Res. 2019, 156, 188-198. [CrossRef]

(C) 2019 by the authors. Licensee MDPI, Basel, Switzerland. This article is an open access article distributed under the terms and conditions of the Creative Commons Attribution (CC BY) license (http://creativecommons.org/licenses/by/4.0/). 